\title{
Análise da disponibilidade de imagens Landsat e Sentinel para o Brasil
}

\author{
Analysis of the availability of Landsat and Sentinel-2 images for Brazil
}
Jean Francois Mas', Carlos Henrique Sopchaki ", Francisco Davy Braz Rabelo "II, Francisca Soares de Araújo ${ }^{\text {"V }}$,Jonathan V. Solórzanov

\begin{abstract}
RESUMO
Este trabalho analisou a disponibilidade de dados sem nuvens dos programas Landsat (refletância da superfície, 1982-2019) e Sentinel-2 (reflectância no topo da atmosfera, 2015-2019) para o território brasileiro. No caso do Landsat, a quantidade de informações disponíveis aumenta consideravelmente em 1999 com o início do Landsat 7. No entanto, principalmente devido à presença de nuvens, a disponibilidade de dados varia muito em espaço e tempo. O bioma Amazônia, em particular, apresenta escassez de dados com uma média de 0,72 observações válidas por mês e com cinco meses com menos de 0,4 observações válidas (dezembro a abril). Os biomas Caatinga e Mata Atlântica também apresentam, em menor grau, poucos dados $(0,96$ e 1,07 observações válidas por mês, em média). Entretanto, outros biomas, como o pampa, apresentam um número significativo de dados (1,44 observações válidas por mês em média para a pampa) distribuídos ao longo do ano de maneira mais regular. O Sentinel-2, devido à melhor resolução temporal, permite alcançar um número maior de observações válidas por mês (cerca de 3 para a Amazônia e 4 para o Pampa). No entanto, a constelação de satélites Sentinel-2 tornou-se totalmente operacional somente em 2018 e, para estudos de períodos históricos, o Landsat, eventualmente combinado com outros sensores, como CBERS ou SPOT, permanece sendo a base de muitos estudos.
\end{abstract}

Palavras-chave: Sensoriamento remoto; Biomas brasileiros; Uso da terra; Fenodinâmica

\section{ABSTRACT}

This paper analyzed the availability of cloud-free data from the programs Landsat (surface reflectance, 1982 2019) and Sentinel-2 (TOA reflectance, 2015-2019) over the Brazilian territory. In the case of Landsat, the amount of information available increased considerably in 1999 with the start of Landsat 7. However, mainly due to the presence of clouds, the availability of data varies greatly in space and time. The Amazon biome, in particular, has scarcity of data with an average of 0.72 valid observations per month and five months with less than 0.4 valid observations (December to April). The Caatinga and Mata Altântica biomes also present, to a lesser extent, little data (0.96 and 1.07 valid observations per month, on average). On the contrary, other

\footnotetext{
Possui doutorado em Ecologia Tropical / sensoriamento remoto pela Université Toulouse III Paul Sabatier(1998). Atualmente é pesquisador da Universidad Nacional Autónoma de Mexico.. E-mail jfmas@ciga.unam.mx. ORCID: http://orcid.org/0000-0002-61389879

" Universidade Federal do Ceará, Departamento de Geografia, Fortaleza. E-mail carlos.geografia@ufc.br . ORCID http://orcid.org/00000001-8127-4529

III Mestre em Geografia pela Universidade Federal do Ceará. E-mail frabelo@uea.edu.br. ORCID http://orcid.org/0000-0003-4326-0729

IV Professora titular na Universidade Federal do Ceará, Departamento de Biologia, Laboratório de Fitogeografia, Fortaleza. E-mail. tchesca@ufc.br ORCID http://orcid.org/0000-0003-4661-6137

$\checkmark$ Estudiante doctorado en laUniversidad Nacional Autónoma de México, Centro de Investigaciones en Geografía Ambiental - Programa de Doctorado en Geografía, Morelia, México. E-mail jonathanvsv@gmail.com . ORCID http://orcid.org/0000-0001-6422-4802
} 
biomes, such as the pampa, present a significant number of data (1.44 valid observations per month on average for pampa) more evenly distributed over the year. Due to its better temporal resolution, Sentinel-2 is able to reach a larger number of valid observations per month (about 3 for the Amazon and 4 for the pampa). However, the Sentinel-2 satellite constellation became fully operational in 2018 and, for studies of historical periods, Landsat, eventually combined with other sensors, such as CBERS or SPOT, remains the basis of many studies.

Keywords: Remote sensing; Land use; Brazilian biomes; Phenodynamics

\section{INTRODUÇÃO}

Com o aumento das atividades humanas, as mudanças antropogênicas na cobertura do solo são mais frequentes e intensivas, especialmente em países com economias em transição como o Brasil. O Instituto Brasileiro de Geografia e Estatística (IBGE) reporta que entre 2000 e 2014, cerca de 13\% do território nacional sofreu algum tipo de alteração da cobertura vegetal, como o desmatamento ou a ampliação das áreas urbanas (IBGE, 2018). De acordo com o Instituto Nacional de Pesquisas Espaciais (INPE), no ano de 2019 houve um acréscimo na taxa de desmatamento na Amazônia Legal de 29,54\% em relação à 2018, atingindo o maior valor de crescimento dos últimos 22 anos (INPE, 2019).

Essas alterações têm múltiplas consequências sobre as mudanças climáticas, a conservação da biodiversidade e as atividades humanas. Copertino et al. (2019) afirmam, por exemplo, que a Amazônia já entrou em um novo regime de clima mais quente e altamente variável, devido ao histórico de desmatamento, e que, por conta desta alteração, houve mudanças no regime de fogo antropogênico, ampliando a magnitude e a quantidade de áreas queimadas. Conforme Lizundia-Loiola et al. (2020), os incêndios apresentam a tendência de aumento segundo os dados dos últimos 17 anos.

Informações, com uma alta resolução espacial e temporal sobre a magnitude e os padrões espaço-temporais das mudanças, são necessárias para avaliar as relações entre as mudanças, suas causas e consequências. O sensoriamento remoto é uma alternativa barata e eficiente para obter informações consistentes sobre a dinâmica espaço-temporal de uso e cobertura da terra. As taxas de desmatamento podem ser avaliadas com base na comparação de imagens de anos diferentes. Porém, mapas de cobertura do solo obtidos para intervalos de tempo longos (por exemplo cada década ou quinquênio) são insuficientes para representar a variações espaço-temporais em paisagens altamente dinâmicas. Da mesma forma, estudos que analisam fenômenos mais dinâmicos como a fenologia da 
vegetação precisam de várias observações intra-anuais para que possam ser analisados os efeitos das alterações climáticas em pequenas escalas temporais. Por exemplo, Zhang et al. (2009) mostram que a fenologia da vegetação pode ser estimada com alta precisão a partir de séries temporais de imagens de satélite com uma resolução temporal de 6 a 16 dias.

Nesse sentido, destacam-se a utilização de imagens oriundas de dois programas específicos, que fornecem produtos de forma gratuita: Landsat e Sentinel-2. Há, em território brasileiro, centenas de trabalhos científicos que foram construídos com a utilização de imagens destes programas, dentre eles: Moreira (1984); Ponzoni et al. (1988); Santos (1994); Mantovani e Pereira (1998); Liesenberg e Lima (2004); Gomes et al. (2011); Bezerra et al. (2019).

O programa Landsat começou em 1972 com resolução espacial de 80m e permitiu adquirir milhões de imagens. Os dados adquiridos a partir do satélite Landsat 4 (1982) têm melhor resolução espacial (30 m), temporal de 16 dias e compreende bandas espectrais no visível e no infravermelho. Foram amplamente utilizados para estudos sobre mudanças no uso do solo (HANSEN; LOVELAND, 2012; HANSEN et al., 2013; SOUZA et al., 2020). No Brasil, diversas pesquisas utilizam produtos oriundos da série Landsat, com destaque para o Projeto PRODES (Monitoramento do Desmatamento da Floresta Amazônica Brasileira por Satélite), SAD (Sistema de Alerta de Desmatamento) e MapBiomas (Projeto de Mapeamento Anual da Cobertura e Uso do Solo no Brasil). Devido à enorme extensão e diversidade do território brasileiro, optou-se por estratificar o processamento das imagens por regiões, delimitadas através dos biomas, como no caso do MapBiomas (SOUZA et al., 2020).

A constelação de satélites Sentinel é uma iniciativa da Agência Espacial Europeia (ESA) dentro do contexto do Programa Copernicus de Observação da Terra. Os diferenciais em relação às outras iniciativas de aquisição de dados são a diversidade de sensores e distintas regiões do espectro eletromagnético compreendidas, partindo do radar e passando por diferentes faixas do espectro, voltadas para diferentes aplicações nos estudos de monitoramento terrestre, oceânico e atmosférico, envolvendo uma gama muito ampla de aplicações. Sete missões foram programadas, referente às operações 1, 2, 3, 4, 5P, 5 e 6, cada com dois satélites necessários para revisitação dos dados de cobertura, além de missões 
contribuintes de diferentes agências e o projeto Copernicus 2.0, contando com seis missões de expansão (BERGER et al., 2012; ESA, 2020a).

A missão Sentinel-2 consiste em um conjunto de dois satélites idênticos (Sentinel-2A e Sentinel-2B) na mesma órbita quase-polar lançados respectivamente em junho de 2015 e março 2017 (ESA, 2020a). Com um único satélite, a revisão periódica é de dez dias no Equador, e com ambos satélites, são cinco dias. Este período é reduzido para 2-3 dias em latitudes médias. Dispõe de um sensor MSI (MultiSpectral Instrument) com 13 bandas espectrais no visível e no infravermelho com uma resolução espacial de 10, 20 e 60 m dependendo da banda (ESA, 2015; MAS et al., 2016 ). Embora a resolução temporal do Landsat 1 ao Landsat 3 seja de 18 dias, do Landsat 4 em diante, seja de 16 dias e do Sentinel2 de cinco dias, a disponibilidade espaço-temporal dessas imagens não ocorre de forma homogênea, ora por conta de políticas de aquisição, ora por conta de condições atmosféricas (presença de nuvens) no momento da tomada da cena, o que pode inviabilizar o uso daquela imagem para determinado fim (Ll; ROY, 2017). Diferentes autores avaliaram a disponibilidade de dados Landsat em várias regiões do mundo como China (ZHOU et al., 2019 ), Estados Unidos (JU; ROY, 2007; EGOROV et al., 2019) e a escala global (JU; ROY, 2007; KOVALSKYY; ROY, 2013). Sendo assim, o objetivo deste estudo é avaliar a disponibilidade de imagens da série Landsat e Sentinel-2 no território brasileiro, buscando verificar se as imagens possuem qualidade e disponibilidade suficientes para apoiar estudos de análise da dinâmica espaço-temporal de uso da terra e de fenodinâmica da vegetação no período de 1982 a 2019 (Landsat) e 2015-2019 (Sentinel-2).

\section{MATERIAL E MÉTODOS}

Foram utilizados dados de refletância da superfície dos sensores Landsat 4 TM, Landsat 5 ETM, Landsat 7 ETM+, Landsat 8 OLI e dados de refletância no topo da atmosfera (TOA, nível 1C) do Sentinel-2 MSI, que se encontram na base de dados de Google Earth Engine (GORELICK et al., 2017).

O Google Earth Engine (disponível em https://earthengine.google.com/) é uma plataforma gratuita, que opera em nuvem e permite manipular dados espaciais com alta 
performance, estando disponíveis diversos dados, como o catálogo Landsat EROS (USGS / NASA), vários conjuntos de dados MODIS, dados Sentinel, dados de precipitação, dados de temperatura da superfície do mar, dados climáticos e dados de elevação (GORELICK et al., 2017; GEE, 2020).

O Google Earth Engine disponibiliza dados de refletância da superfície (nível 1A) para o Sentinel-2, todavia, dependendo da região do mundo, estão disponíveis a partir de 2017 ou 2018. Os dados Landsat passam por correção atmosférica, sendo utilizado o sistema de processamento Landsat Ecosystem Disturbance Adaptive Processing System (LEDAPS) para o Landsat 4 a 7; e o Land Surface Reflectance Code (LaSRC) para o Landsat 8. Cabe destacar ainda que dados Landsat incluem uma máscara de nuvem, sombra, água e neve produzida produzida com uso do algoritmo C Function of Mask (CFMASK), bem como uma máscara de saturação por pixel (USGS, 2020). Foram utilizados unicamente os dados da coleção Tier 1 que contém as imagens processadas com elevada qualidade radiométrica e geométrica, intercalibradas entre os sensores da série Landsat e recomendadas pelo USGS para análises de séries temporais. Os dados Sentinel-2 apresentam uma banda de qualidade com uma resolução de 60m (QA60) que indica a presença de nuvens (ESA, 2020a).

Os sensores a bordo do Landsat possuem uma faixa de imageamento de $185 \mathrm{~km}$ de largura, as cenas são porções dessa faixa de 170 km norte-sul. No caso do Sentinel-2, a faixa de imageamento tem $290 \mathrm{~km}$ de largura (DRUSCH et al., 2012), contudo, a partir de certo nível de processamento (1C e 2A), os dados não são distribuídos como cenas, mas sistematizados e distribuídos como "granules" ou "tiles", que são ortoimagens de 110 km por 110 km na projeção UTM / WGS84 (ESA, 2020a). Os tiles localizados no limite entre duas faixas de mapeamento têm uma área sem informação, os dados que correspondem a outra faixa se apresentam em outro tile para evitar um mosaico de imagens de datas diferentes (Figura 1). As imagens Sentinel podem ser obtidas no site do centro científico Copernicus (https://scihub.copernicus.eu/). Ambos dados, Landsat e Sentinel-2, estão também disponíveis no site do serviço USGS EarthExplorer (http://earthexplorer.usgs.gov/) e no Google Earth Engine (GEE). 
Figura 1 - Exemplo de tiles localizados no limite entre duas faixas de imageamento do Sentinel-2. A faixa verde na imagem da esquerda representa a área de sobreposição entre duas faixas de mapeamento. As imagens desse tile são portanto incompletas devido ao recobrimento parcial dessas faixas.
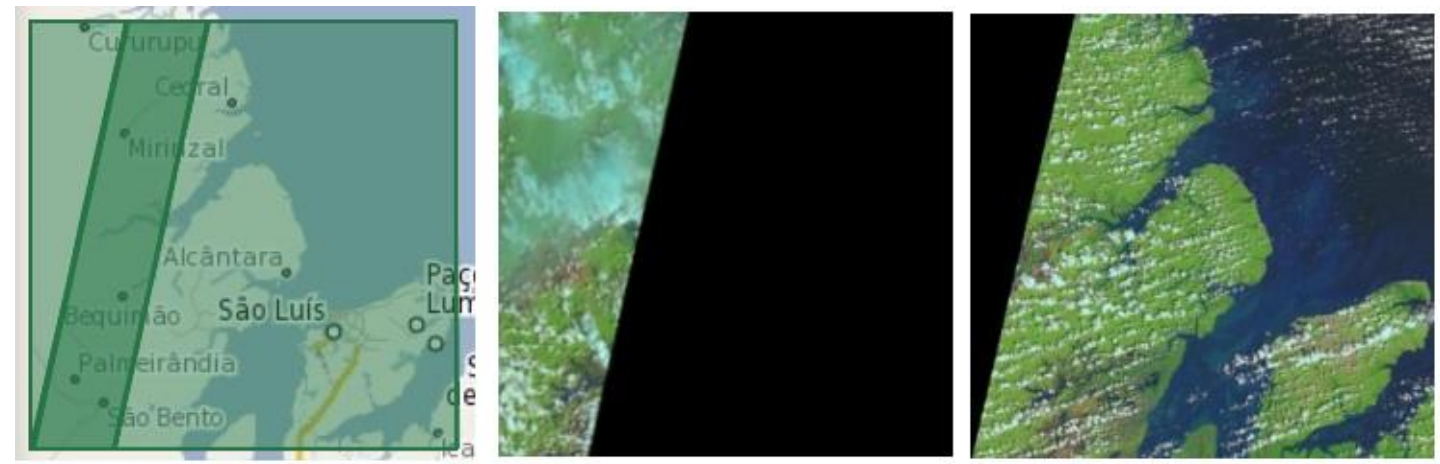

Fonte: ESA, organizado pelos autores (2020).

Foi realizado um levantamento dos produtos disponibilizados para o Brasil pelo Landsat 4 (L4), Landsat 5 (L5), Landsat 7 (L7) e Landsat 8 (L8) de 1982 a 2019, e Sentinel-2 de 2015 a 2019, a nível de cenas / tiles e de pixels, procurando avaliar as áreas e as várias janelas temporais idôneas para monitorar mudanças nos tipos de cobertura do solo e estudos baseados em uma alta resolução temporal. A nível de cenas (path/row) se analisaram os metadados das imagens para determinar o número total de imagens e sua distribuição espacial e destas, quantas possuíam menos de $50 \%$ de nuvens. No caso do Sentinel-2, os dados estão organizados em tiles, o que dificulta a comparação com Landsat. A soma do número de tiles poderia levar a superestimar a quantidade de dados disponíveis no caso dos tiles que contém duas faixas de imageamento do satélite, dessa forma os dados se dividem entre dois tiles. Por esta razão, nestes casos só se contabilizou um entre os dois tiles com informação parcial.

Foi determinada também a contribuição dos diferentes sensores na obtenção das imagens ao longo do tempo a nível de pixel. A data da imagem foi levada em consideração a fim de evitar contabilizar duas vezes a mesma observação nas faixas de sobreposição entre duas cenas ou tiles. Realizou-se uma análise regional para avaliar a disponibilidade de observações válidas por bioma e avaliou-se também a distribuição espacial e temporal das observações válidas (sem nuvens). Para apresentar a distribuição das observações válidas ao 
longo do ano nos diferentes biomas, foram elaborados mapas de calor. O gradiente de cor padrão atribui o valor mais baixo no mapa a vermelho escuro, o valor mais alto é atribuído a verde e os valores do meio apresentam uma transição (ou gradiente) correspondente entre esses extremos. Combinou-se os mapas de calor com um cluster hierárquico representado por um dendrograma, que é uma estrutura em árvore da hierarquia. Os dendogramas de linha mostram a semelhança entre os padrões de distribuição temporal das observações válidas dos biomas. A busca de imagens e o processamento na base de dados de GEE foi executada através da programação de código do Earth Engine Code Editor, disponível em: https://code.earthengine.google.com/ (GORELICK et al., 2017). As análises estatísticas, os gráficos e os mapas foram elaborados com o software R (MAS et al., 2019; R CORE TEAM, 2020). 


\section{RESULTADOS}

\subsection{Análise a nível de cenas}

Não foram encontradas imagens Landsat 4 para os anos de 1982 e 1983 no nível de processamento requerido. Nas Figuras 2 e 3 é apresentado o número total de imagens obtidas para cada um dos satélites Landsat (L4, L5, L7 e L8) para o período de 1984 a 2019, e pelo Sentinel-2A e Sentinel-2B para o período de 2015 a 2019 para o território brasileiro.

Com relação ao número total de imagens obtidas pelos diferentes satélites Landsat ao longo do tempo (Fig. 2), chama a atenção que, devido a vida útil longa, dois satélites (L5 e L7) são responsáveis pela maioria das imagens para este período. Cabe destacar também que há uma heterogeneidade com relação ao total de imagens/ano, principalmente na era do Landsat 5, onde há variações desde menos de 5000 imagens/ano até 15000 imagens/ano. Contudo, o Landsat 7 e principalmente o Landsat 8 apresentam uma variação menor no total de imagens/ano, ficando por exemplo, o Landsat 8 sempre com cerca de 5000 imagens/ano, com exceção de seu primeiro ano de operação. É importante lembrar que a partir do 31 de maio 2003, o Landsat 7 teve um problema técnico no equipamento eletro-mecânico chamado Scan Line Correction (SLC) e as imagens apresentam espaços vazios, causando uma perda de $22 \%$ dos dados (CHEN et al., 2011). 
Figura 2 - Número de imagens obtidas pelos diferentes satélites Landsat ao longo do tempo (1984 a 2019)

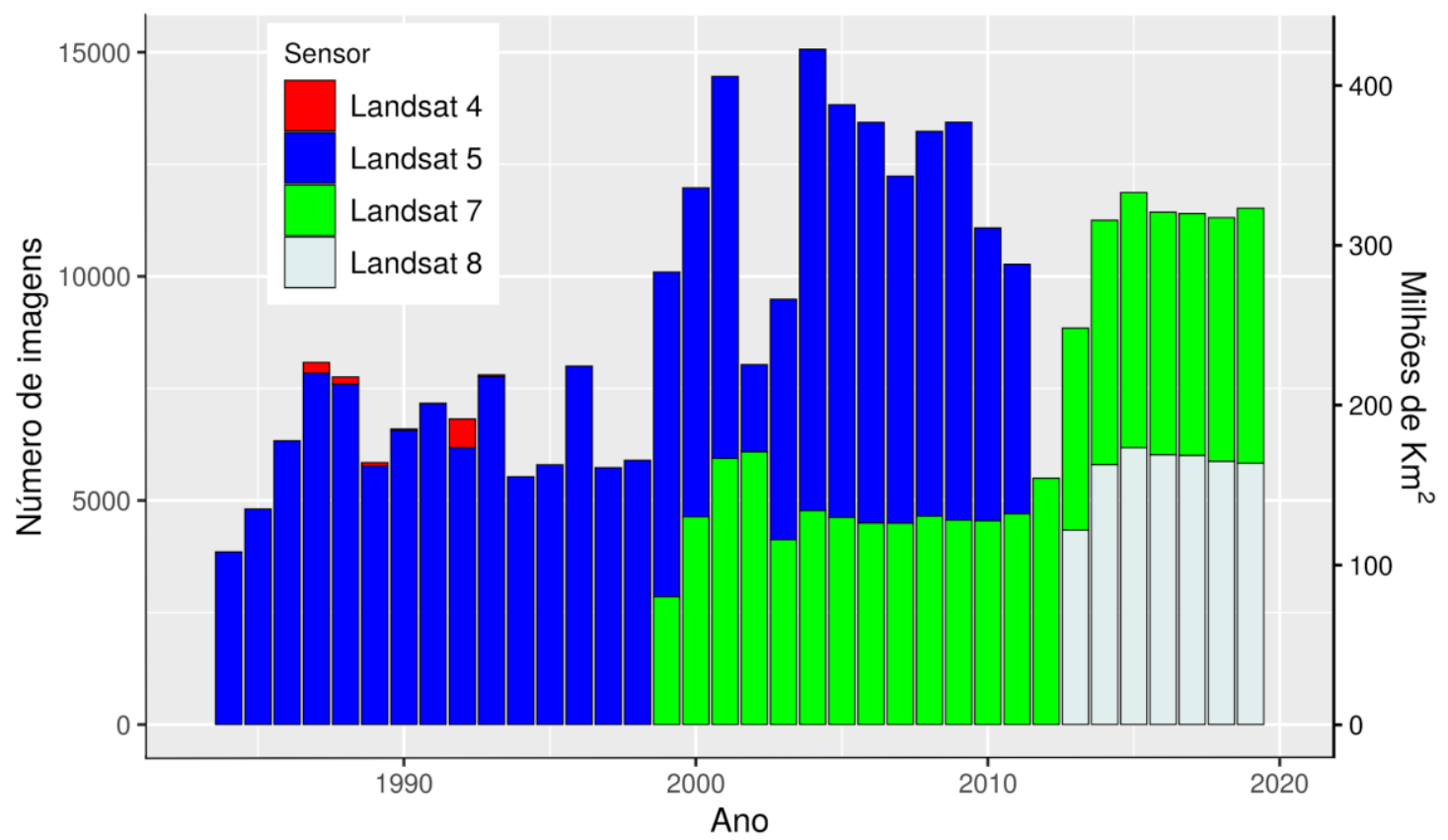

Fonte: Autores/as (2020)

Essa heterogeneidade não se apresenta para as imagens do Sentinel-2 (Fig. 3), pois, para o período analisado (2015 a 2019), com exceção dos primeiros anos de operação dos satélites (2015 para o Sentinel-2A e 2017 para o Sentinel-2B), pode-se dizer que o Sentinel2A apresenta sempre cerca de 30000 imagens/ano. Ao se comparar a disponibilidade total de imagens por ano para ambos os satélites (Landsat e Sentinel-2), é possível inferir que o Sentinel-2 é responsável por disponibilizar uma maior área imageada anualmente, superior a 600 milhões de $\mathrm{Km}^{2}$, enquanto que no Landsat essa área chega até cerca de 350 milhões de $\mathrm{Km}^{2}$. As diferenças entre o Landsat e o Sentinel-2 podem ser explicadas, entre outros fatores, pela desigualdade na resolução temporal dos satélites (Landsat: 16 dias; Sentinel-2: cinco dias em operação conjunta entre os dois satélites). 
Figura 3 - Número de imagens obtidas pela constelação Sentinel-2 ao longo do tempo (2015 a 2019)

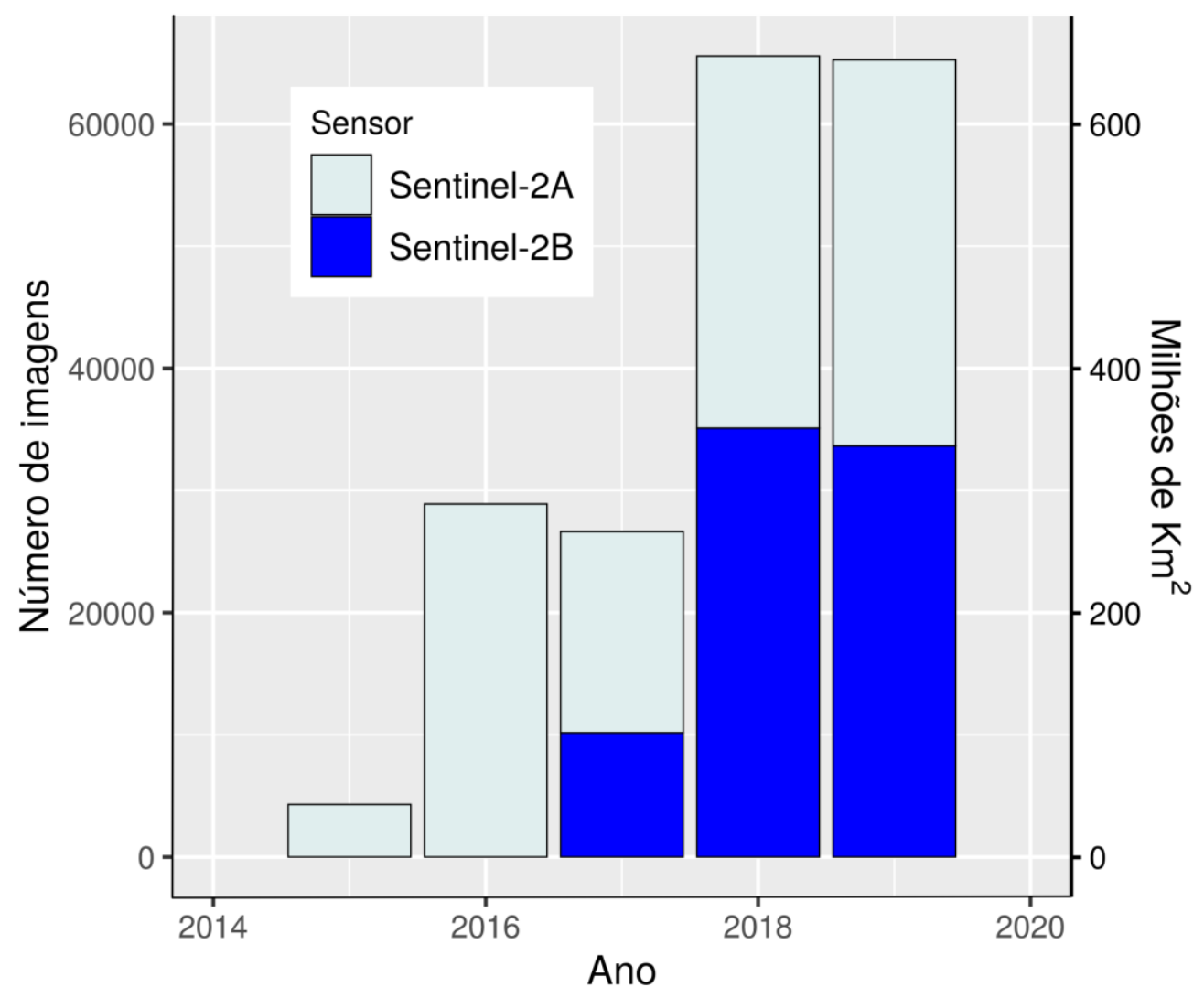

Fonte: Autores/as (2020)

Os resultados inerentes ao total de imagens Landsat por cena (path/row) e número total de imagens por cena com cobertura de nuvens menor do que $50 \%$ para os satélites Landsat (período de 1984 a 2019) e Sentinel-2 (período de 2015 a 2019) são apresentados na Figura 4. 
Figura 4 - Número total de imagens por cena (path/row) e número total de imagens por cena com cobertura de nuvens menor do que $50 \%$ para os satélites Landsat 4 a 8 (período de 1984 a 2019) e Sentinel-2 (período de 2015 a 2019).
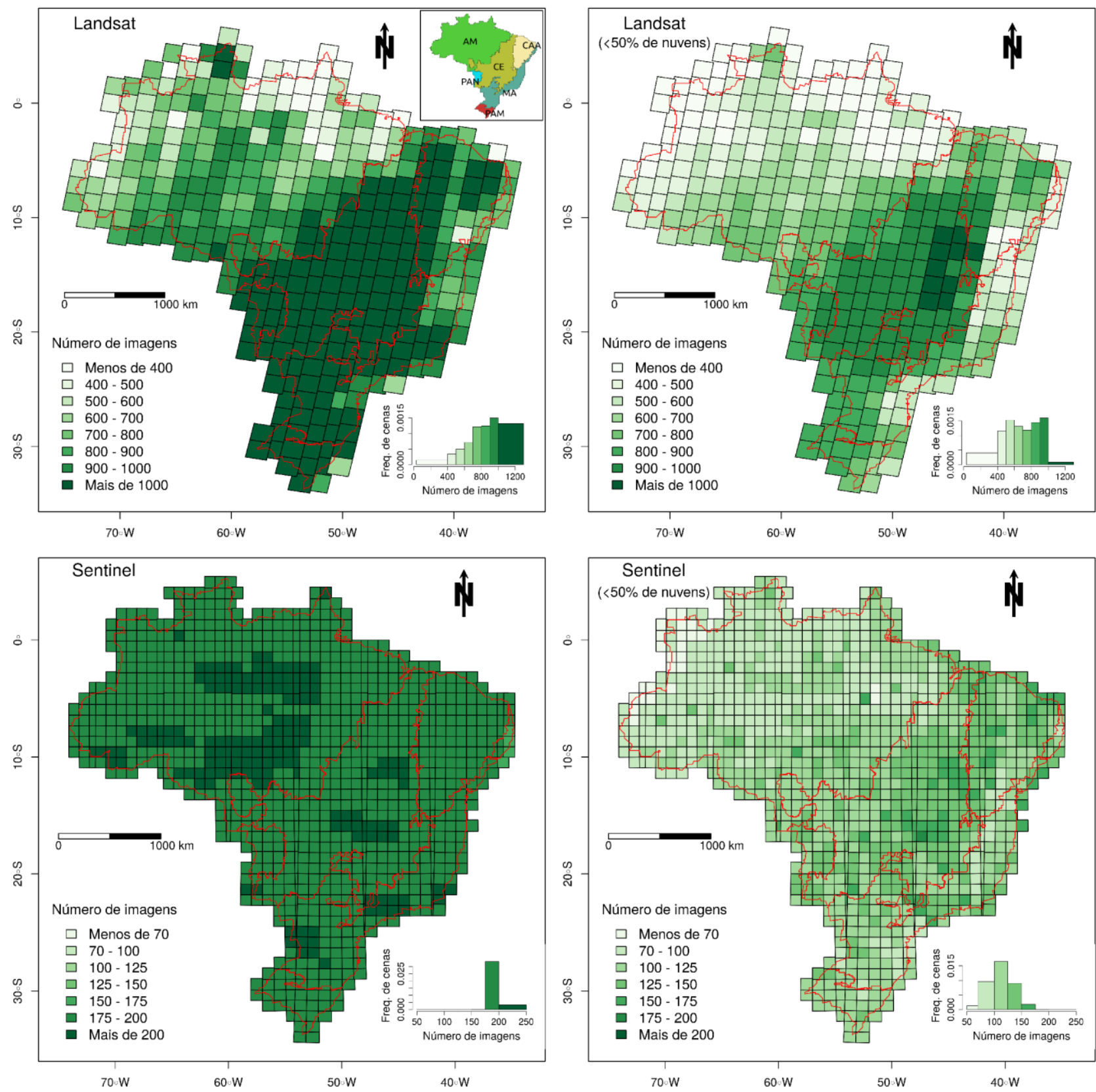

Fonte: Autores/as (2020)

Com relação ao Landsat, é possível observar que há certa discrepância espaçotemporal na disponibilidade de imagens distribuídas ao longo do território brasileiro, no período de 1984 a 2019. As cenas com mais de 1000 imagens se concentram nos biomas Cerrado, Pantanal, Mata Atlântica, Pampa e parte da Caatinga. Cabe destacar que o Bioma 
Pantanal está completamente coberto por cenas com mais de 1000 imagens e que o Bioma Pampa também é quase que exclusivamente coberto por essas cenas, com exceção de uma pequena porção ao leste, que corresponde a uma cena que engloba pequena área continental, predominando a cobertura do oceano. Por sua vez, o Bioma Cerrado possui somente cinco cenas com menos de 1000 imagens, mas com disponibilidade sempre superior a 600 imagens. Disponibilidade menor de imagens é encontrada na região nordeste no Bioma Mata Atlântica, em grande parte do Bioma Caatinga, e principalmente no Bioma Amazônia. Este apresenta a maior heterogeneidade e os piores valores de quantidades de cenas disponíveis no território brasileiro, com diversas cenas com menos de 400 imagens até algumas com mais de 1000 imagens. Vale ressaltar que o número muito pequeno de imagens para determinadas cenas, principalmente na Amazônia, se deve ao fato de um número significativo de imagens estarem na coleção Tier 2, na qual são encontrados dados que não atenderam aos critérios de qualidade durante o pré-processamento devido a presença de nuvens.

Ainda no que se refere ao Landsat, ao se observar o total de imagens com menos de 50\% de nuvens, pode-se inferir que os piores valores estão igualmente no Bioma Amazônia, que possui a maioria da sua área coberta por cenas com menos de 400 imagens com esse padrão de qualidade. Destacam-se também duas porções ao leste do Bioma Mata Atlântica e algumas cenas no Bioma Caatinga. As outras porções destes Biomas, bem como os demais Biomas (Pampa, Pantanal e Cerrado) apresentam uma distribuição mais homogênea de cenas com menos de $50 \%$ de nuvens, predominando valores acima de 700 cenas nesta condição.

Conforme exposto anteriormente, o número de imagens disponíveis do Sentinel-2 apresenta uma distribuição mais regular, sendo que há algumas cenas com mais de 200 imagens disponíveis e o restante do território é todo coberto por cenas que disponibilizam entre 175 e 200 imagens. Contudo, no que concerne à imagens com menos de 50\% de nuvens, verifica-se que a distribuição é heterogênea para todos os Biomas, variando de cenas com menos de 50 imagens até cenas entre 150 e 175 imagens, predominando cenas que variam entre 100 e 125 imagens. 


\subsection{Análise a nível de pixel}

As figuras 5 e 6 apresentam o número total de observações (pixels) válidas (sem nuvens) para o período 1984-2019 (Landsat) e 2015-2019 (Sentinel-2), ou seja, quantas vezes cada pixel foi apresentado na imagem com ausência de nuvens no decorrer de tais períodos. Cabe destacar que a escala de cores entre as figuras não é similar, variando no Landsat de zero (vermelho) a 1300 (verde escuro), e no Sentinel-2 de zero (vermelho) a 350 (verde escuro)

Figura 5 - Número de observações Landsat válidas a nível de pixel (1984-2019). As linhas azuis indicam os limites dos biomas brasileiros.

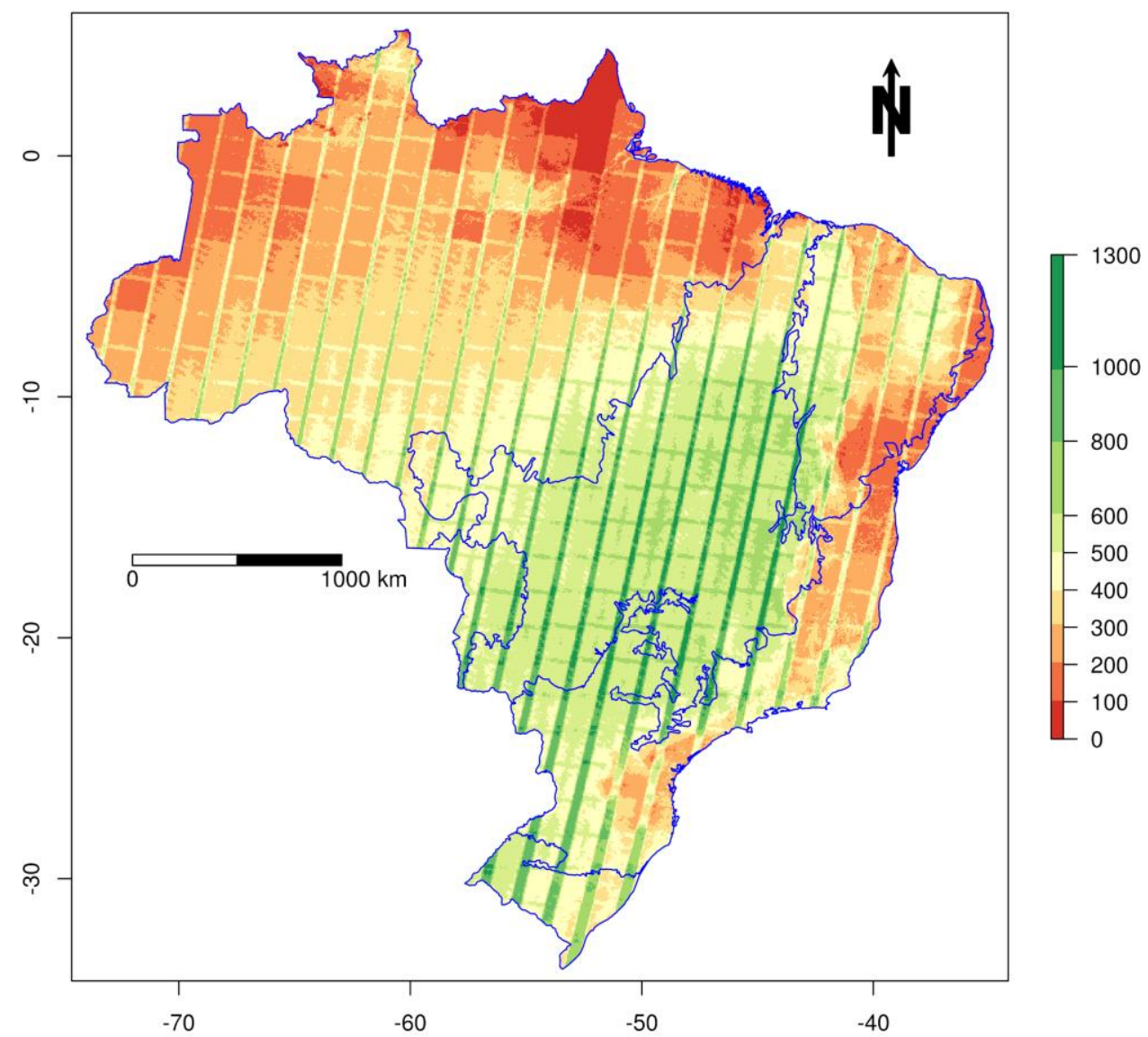

Fonte: Autores/as (2020)

Com relação aos pixels válidos (com ausência de nuvens) para as imagens do Landsat (Fig. 5), percebe-se que os biomas que possuem maior número de repetições e também maior homogeneidade na distribuição de tais repetições são o Cerrado, Pantanal e Pampa. 
Pode-se dizer que quase a totalidade de tais biomas está coberto por pixels que tiveram mais de 600 observações válidas para o período. Há ainda uma particularidade em relação ao bioma Mata Atlântica, no sul, entre o Cerrado e o Pampa. Salvo a porção leste deste bioma nesta região, é possível inferir que o restante segue um padrão similar de distribuição de pixels válidos em relação aos biomas Cerrado, Pantanal e Pampa. Nestas regiões do bioma Mata Atlântica, mais afastadas da Serra do Mar e da Planície Litorânea que abrangem o Segundo e Terceiros Planalto (MAACK, 1968), predominam Floresta Ombrófila Mista, Estepe (Campos Naturais) e Floresta Estacional Semidecidual (IBGE, 2012). Portanto, por tais áreas estarem mais distantes do litoral e da encosta da Serra do Mar, apresentam menor porcentagem de cobertura de nuvens.

A Amazônia é o bioma com as menores quantidades de pixels válidos, apresentando os piores valores nos setores noroeste e nordeste. No nordeste há uma baixa disponibilidade de pixels válidos no litoral equatorial amazônico, no Amapá e na região bragantina no Pará, área constituída por vales fluviais afogados, com presença marcante de manguezais, conforme setorização de Ab'sáber (2005). Outros trechos com baixas disponibilidades de pixel válidos são o extremo noroeste do bioma, fronteiras com a Colômbia e Venezuela, o qual apresenta superfícies aplainadas; e o setor norte-nordeste, no planalto do divisor Amazonas-Orinoco, fronteiras com Venezuela e Guiana, com extensa área montanhosa (MAIA; MARMOS, 2010). 


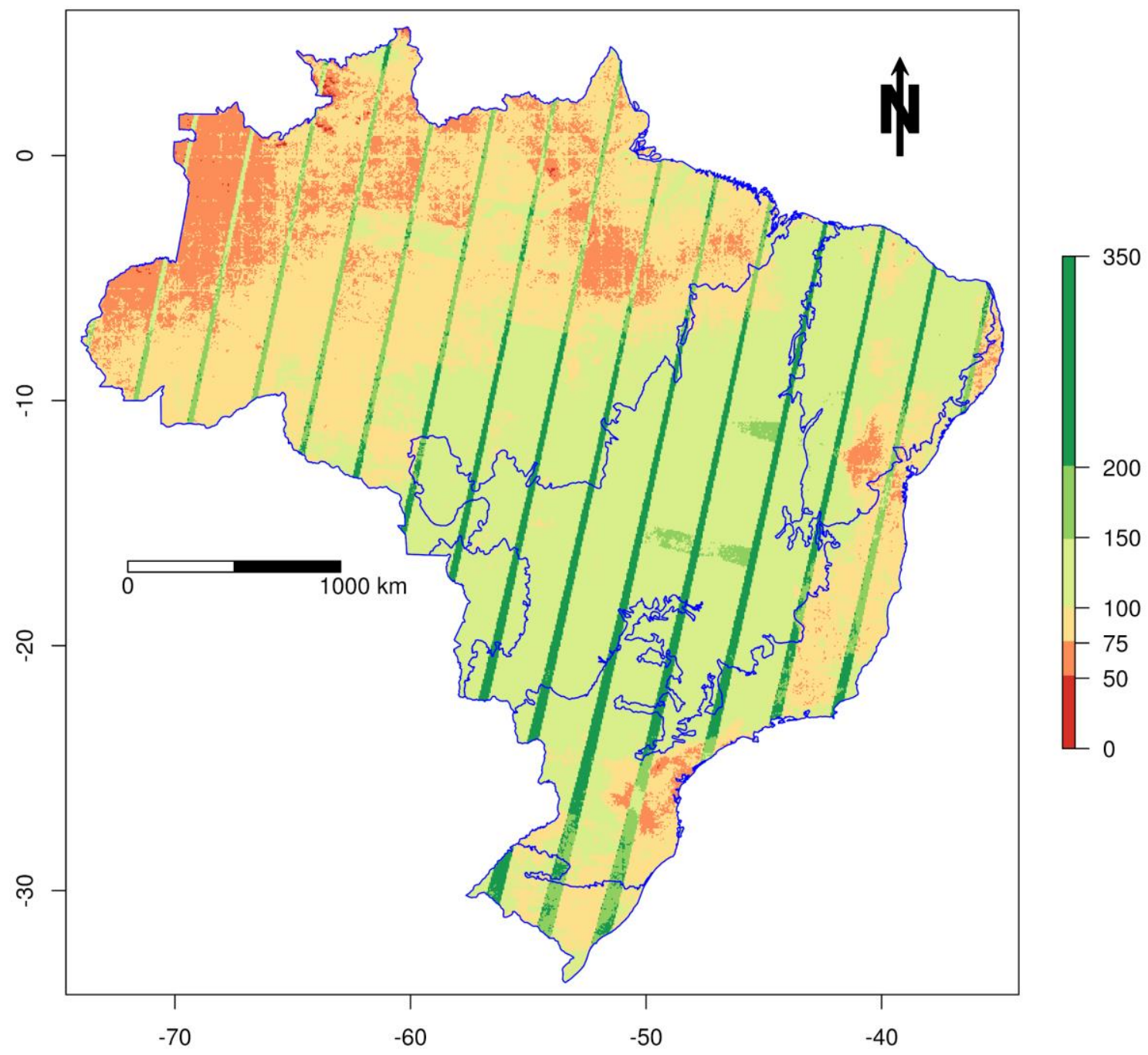

Fonte: Autores/as (2020)

No que concerne aos pixels válidos (com ausência de nuvens) para as imagens do Sentinel-2 (Fig. 6), embora, conforme destacado anteriormente, a escala de cores entre as figuras do Landsat e Sentinel-2 não seja similar (assim como o período analisado), pode-se dizer que os padrões de distribuição do número total de observações (pixels) válidas (sem nuvens) são próximos aos do Landsat, tanto no território brasileiro como um todo, quanto no tocante aos biomas. Contudo, o número absoluto de observações válidas por ano é maior para o Sentinel-2. Por exemplo, durante 2018-19, a média de observações anuais válidas é 13,4 e 41,9 para o Landsat 7/8 e o Sentinel-2, respectivamente. Essa diferença pode ser explicada pela melhor resolução temporal do Sentinel-2 e pelas perdas de dados do Landsat 
7. No entanto, é provável que o número de observações válidas do Sentinel-2 seja superestimada devido ao baixo desempenho da máscara de nuvem. Coluzzi et al. (2018) avaliaram a máscara de nuvem do Sentinel-2 L1C e descobriram que geralmente subestima a presença de nuvens (erro de omissão médio 37,4\%). A detecção das nuvens nas regiões florestais tropicais da Amazônia foi particularmente ineficiente (Erro de omissão > 70\%) devido à presença de nebulosidade complexa e do alto conteúdo de vapor de água.

Outro aspecto interessante que pode ser observado nas figuras 5 e 6 são faixas orientadas norte-sul nas quais há aproximadamente o dobro de observações válidas. Essas áreas correspondem à sobreposição entre duas faixas de imageamento do satélite e são mais estreitas no nível do equador (aproximadamente $20 \mathrm{~km}$ de largura) e mais amplas em altas latitudes (75 km no Sentinel-2 e 60 km no Landsat no sul do país). Também podem ser observadas faixas verticais correspondentes à área de sobreposição entre duas cenas da mesma faixa de imageamento. Nesse caso, como a máscara de nuvem é aplicada independentemente para cada cena, os pixels têm duas "oportunidades" para serem classificados como sem nuvens e, consequentemente, apresentam um número um pouco maior de observações válidas do que as áreas não sobrepostas. No entanto, observa-se que os pixels classificados sem nuvem nas duas cenas são contados apenas uma vez, devido ao filtro baseado na data de aquisição da imagem.

As figuras 7 e 8 apresentam o número total de observações válidas mensais para Landsat (1984 a 2019) e Sentinel-2 (2018 a 2019). O fato de serem apresentados somente dois anos inerentes ao Sentinel-2 ocorre porque a constelação de satélites Sentinel-2 tornou-se totalmente operacional somente em 2018, sendo este o primeiro ano com dado completo para todo o período (ESA, 2018). 
Figura 7 - Número médio de observações Landsat válidas mensalmente a nível de pixel (1984-2019)
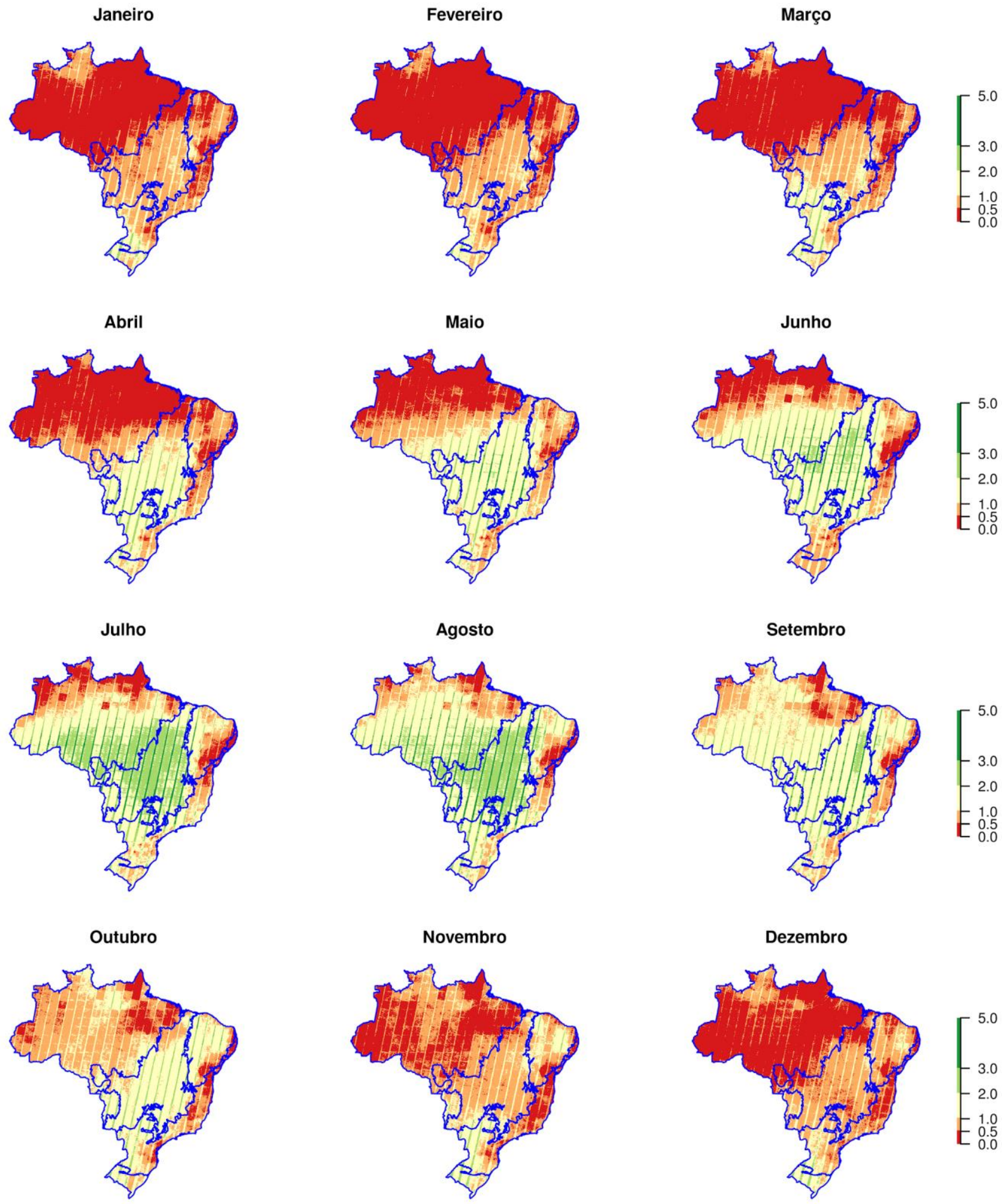

Fonte: Autores/as (2020) 
Figura 8 - Número médio de observações Sentinel-2 válidas mensalmente a nível de pixel (2018-2019)

Fonte: Autores/as (2020)
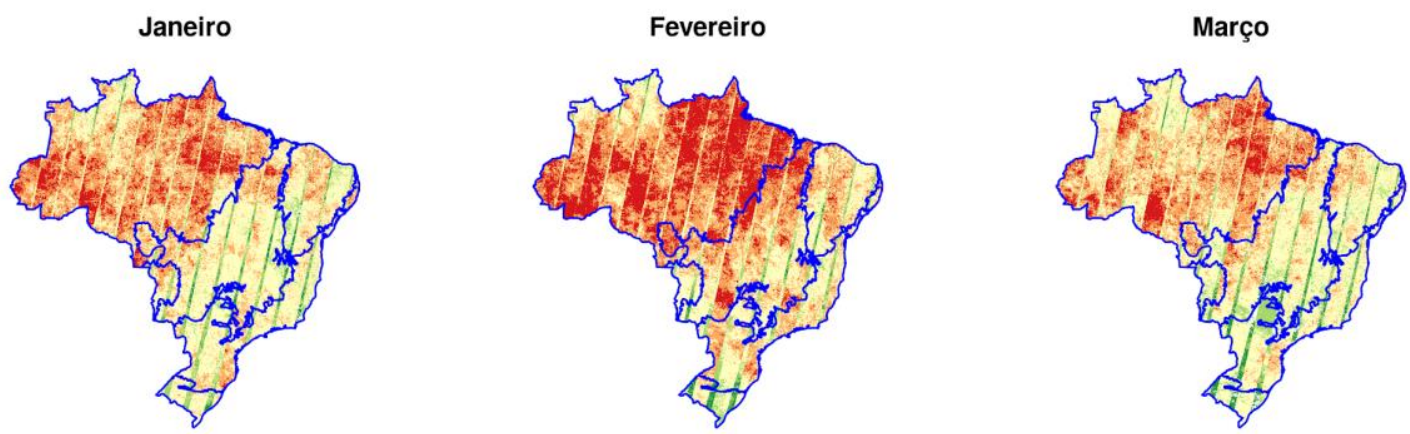

$F^{8}$
-6
-4
$E_{0}^{2}$
0
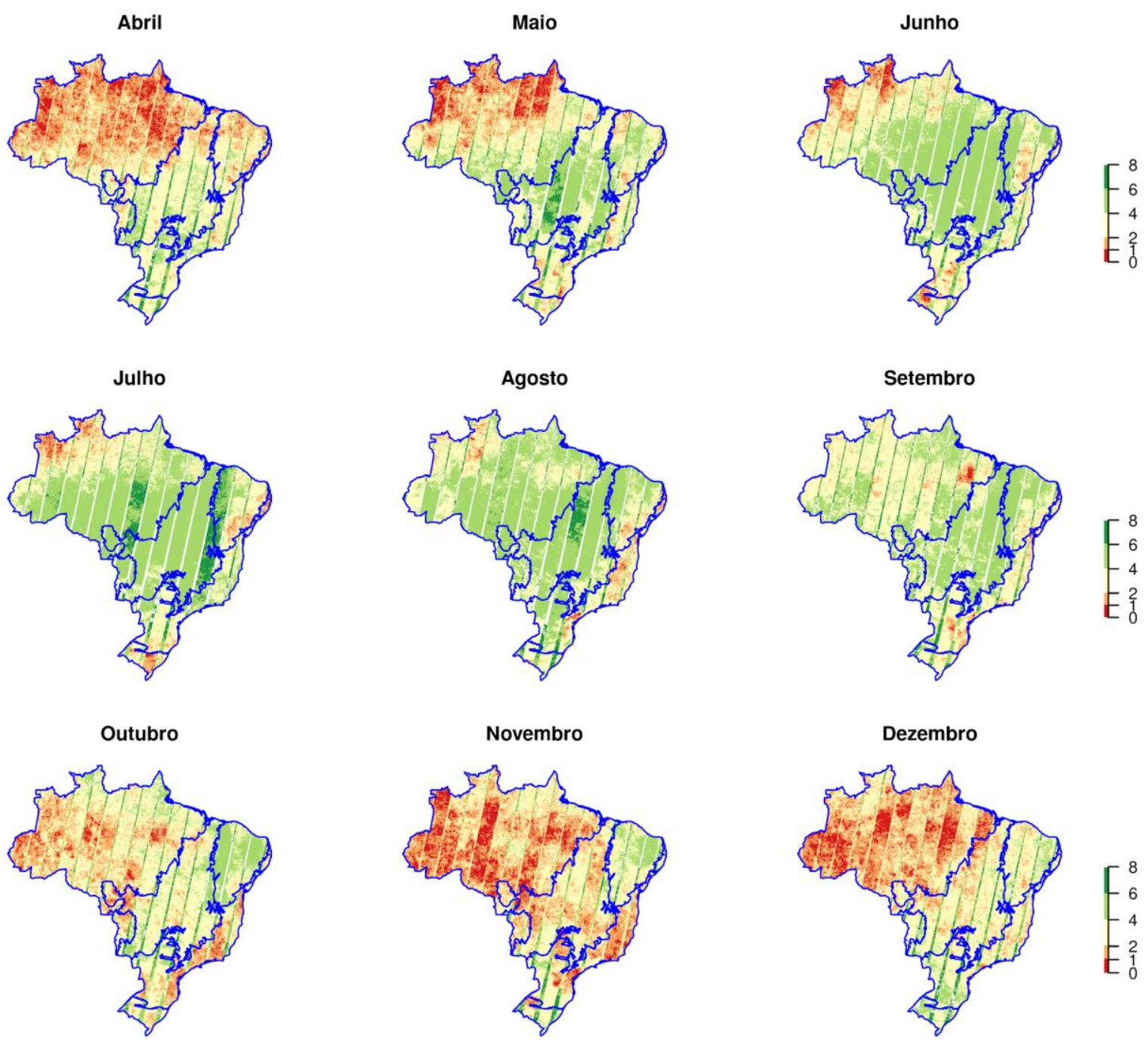

Fonte: Autores/as (2020) 
Baseado nas figuras 7 e 8, pode-se perceber uma escassez de observações válidas durante o período entre os meses de novembro a maio, principalmente nos biomas Amazônia e Caatinga e sobretudo com os dados do Landsat. Os mapas de calor (Figuras 9 e 10) permitem sintetizar esta informação. Com base nos dados do Landsat, o Bioma Amazônia, seguido, em menor grau, pela Caatinga e pela Mata Atlântica são os que apresentam a maior falta de dados válidos ao longo do ano. Ao contrário, o bioma Pampa foi o que apresentou a melhor distribuição temporal de observações. O padrão observado com os dados do Sentinel-2 é um pouco diferente. Em geral, existe uma maior quantidade de observações mensais válidas (em média 3,8 para o Sentinel-2 e 1,1 para o Landsat). O Pampa segue um padrão particular, com dados relativamente abundantes ao longo do ano. A Caatinga e a Mata Atlântica foram novamente agrupadas por sua similaridade no padrão espaço-temporal das observações válidas. A Amazônia continua a apresentar o padrão mais adverso, com aproximadamente duas observações mensais válidas durante cinco meses do ano.

Figura 9 - Número médio de observações Landsat válidas mensalmente por bioma (19842019)

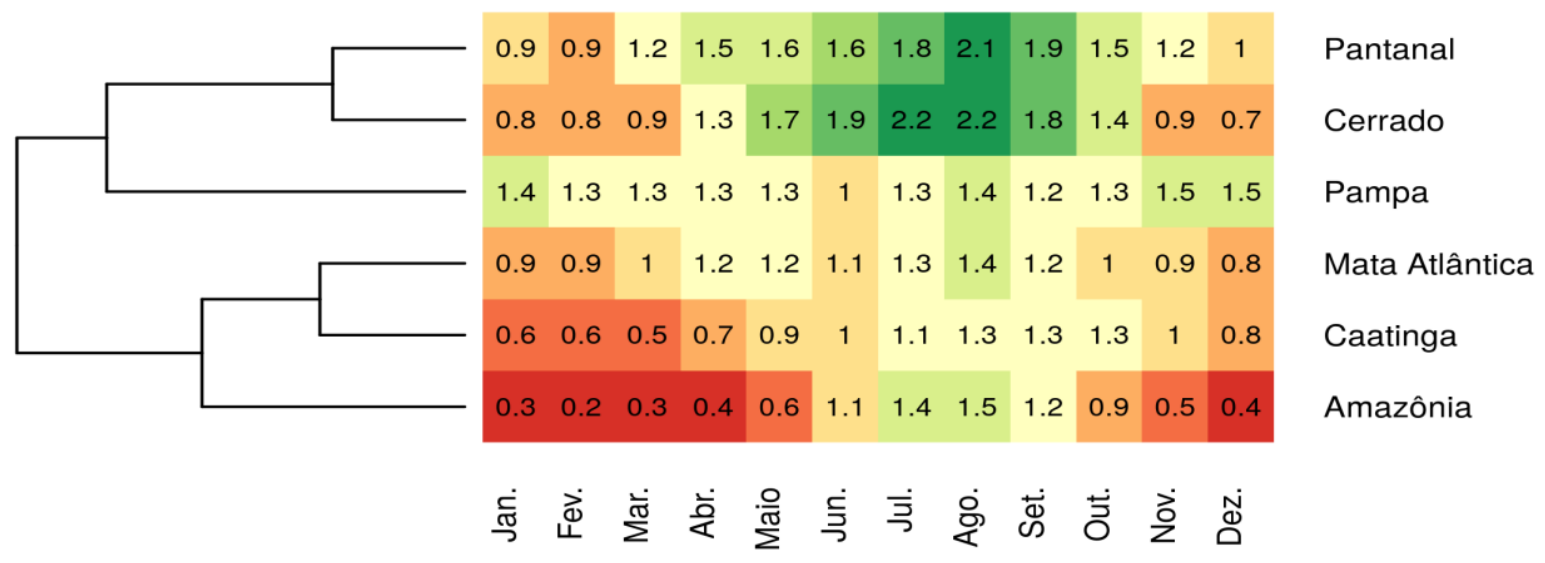

Fonte: Autores/as (2020) 
Figura 10 - Número médio de observações Sentinel-2 válidas mensalmente por bioma (2018-2019)

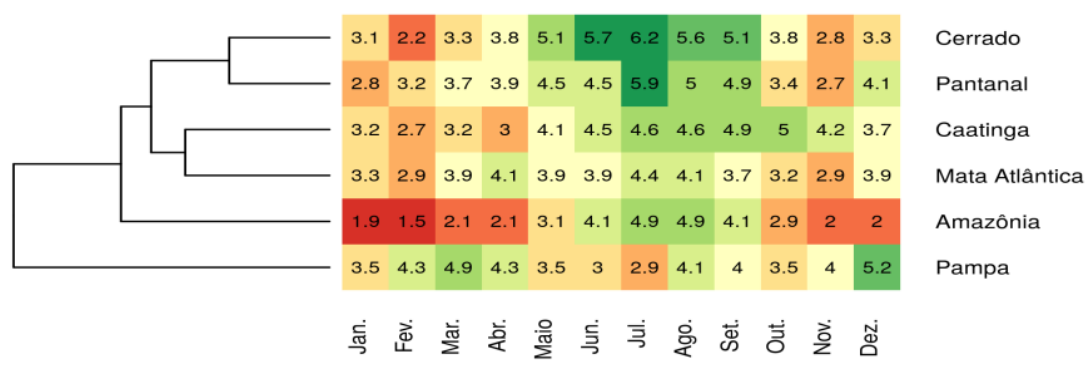

Fonte: Autores/as (2020)

\section{DISCUSSÃO}

A aquisição de dados, em especial no sensoriamento remoto passivo em nível orbital, depende diretamente das condições atmosféricas, que são dinâmicas, haja vista que entre os alvos a serem registrados e o sensor existe a atmosfera terrestre, e portanto, na detecção da cena a presença de nuvens pode inviabilizar o registro dos alvos, além dos efeitos de absorção e espalhamento atmosféricos, mesmo com pouca nebulosidade (NOVO, 2008; JENSEN, 2009). Segundo Barry e Chorley (2013), na troposfera grande parte da circulação atmosférica é regulada pelas diferenças térmicas. De acordo com Monteiro (2007), na troposfera "o normal é a temperatura diminuir com a altitude em uma média de $0,65^{\circ} \mathrm{C}$ para cada 100 metros". O autor afirma que mudanças de temperaturas superiores a esse valor médio tornam o ar instável e favorecem a formação de nebulosidade. Nas zonas intertropicais esse fenômeno é ainda mais presente, inviabilizando muitas vezes uma disponibilidade de dados temporais mais efetiva por conta da intensa nebulosidade.

No contexto das regiões tropicais existem diversos sistemas meteorológicos, sendo que dois deles são bastante atuantes em escala sinótica no Brasil: Zona de Convergência Tropical (ZCIT) e Zona de Convergência do Atlântico Sul (ZCAS). A ZCIT é uma banda de nebulosidade convectiva, formada pela confluência dos ventos alísios de NE e alísios de SE, 
associada à baixa pressão atmosférica na região do Equador, em uma zona de instabilidade influenciada diretamente pela temperatura da superfície do mar (TSM), atuando principalmente na costa norte do Brasil, nos biomas Caatinga e Amazônico, tendo os meses de março e abril com maior destaque (MELO et al., 2009; ROSA; SILVA, 2016). A ZCAS é um grande corredor de umidade com nuvens carregadas, em sentido noroeste-sudeste abrangendo setores dos biomas Amazônico e Mata Atlântica, formada pela confluência de frentes frias bloqueadas sobre o sudeste, alimentada pela umidade oriunda da região norte nas áreas mais elevadas durante o verão (SILVA et al., 2019).

Como exemplo, no bioma amazônico, em relação ao número médio de observações mensais (figuras 7 e 8), é marcante a atuação desses e outros sistemas atmosféricos que influenciam na quantidade de nebulosidade e na baixa disponibilidade de pixels com ausência de nuvens, principalmente nos meses de janeiro a maio, e novembro e dezembro, correspondendo aos períodos de maiores precipitações e intensa nebulosidade. Já a disponibilidade efetiva está mais presente nos meses de junho, julho e agosto, correspondente à estação seca, até meados de outubro.

Cabe destacar também a influência do Fenômeno El Niño-Oscilação Sul (ENOS), que consiste em alterações acima da média histórica na temperatura do Oceano Pacífico Equatorial, sendo denominado El Niño, quando há aquecimento, e La Niña, quando ocorre o resfriamento. Com relação à precipitação, numa escala a nível de Brasil, pode-se afirmar que, em geral, o El Niño reduz as chuvas na região norte do país, traz risco de secas severas na região nordeste, e gera chuvas intensas na região sul (principalmente de maio a julho). Por outro lado, o fenômeno La Niña gera aumento de precipitação nas regiões norte e nordeste e redução drástica no sul. (CPTEC-INPE, 2020; FREIRE; LIMA; CAVALCANTI, 2011). Tais fatores podem acarretar numa maior presença de nuvens nas cenas dos satélites em épocas de ENOS, em diferentes regiões e biomas brasileiros, de acordo com o sistema atuante (El Niño ou La Niña).

Vilani et al. (2010) esclarecem que as condições de nebulosidade estão diretamente relacionadas com a precipitação, consequentemente influenciando na reflectância e transmitância da atmosfera. Dessa forma, Asner (2001) aponta que as limitações impostas pela nebulosidade para mapeamento com dados do Landsat para o bioma amazônico são 
grandes, sendo este um problema já relatado na literatura em relação a disponibilidade de dados orbitais de sensoriamento remoto. Existem também limitações de disponibilidade nas áreas de transição entre Amazônia e Cerrado, com nebulosidade mais densa e persistente, por conta das condições atmosféricas (SANO et al., 2007).

Contudo, pode também haver variações nessa dinâmica climatológica ocasionado por períodos de secas. Franca e Mendonça (2016) destacam que águas mais frias deslocam a ZCIT para o sentido norte, causando anos secos ou muito secos na região amazônica, ocorrendo o inverso quando a TSM do atlântico sul tropical, mais aquecida, favorece anos mais chuvosos nessa área. Nessa perspectiva, no contexto das observações válidas, há uma menor repetição e ausência de dados em especial no noroeste, norte-nordeste e nordeste do bioma amazônico. No caso do setor norte-nordeste do bioma amazônico, correspondente a uma parcela do estado do Amapá, há uma convergência de diferentes fatores meteorológicos que intensificam a nebulosidade durante praticamente todo o ano, oriundo da atuação da ZCIT e de fenômenos de mesoescala como as Linhas de Instabilidade (LIs) (AMANJÁS, 2012; TAVARES, 2014). É importante destacar que apesar do fator climatológico ser muitas vezes preponderante, diferentes características geomorfológicas, fitogeográficas e de evapotranspiração podem intensificar o fenômeno da nebulosidade, seja na sua amplitude ou persistência, repercutindo diretamente na ausência de uma cobertura de dados em determinados setores e em sua distribuição ao longo do tempo.

A disponibilidade dos dados do Landsat é suficiente para monitorar o uso das mudanças no uso da terra em todo o território brasileiro, com base na comparação de imagens espaçadas por vários anos a partir da década de 1980. Esse tipo de monitoramento é comumente realizado no país (GRECCHI et al., 2016) inclusive na Amazônia (SAMPAIO e WACHHOLZ, 2018). A realização de monitoramento das mudanças no uso da terra com melhor resolução temporal (um mapa por ano) e para períodos anteriores a 2000 enfrentará problemas de falta de observações válidas em vários biomas, particularmente na Amazônia, mas também na Caatinga e na Mata Atlântica. Nesses casos, será necessário recorrer a estratégias como a criação de composições de várias datas ou a combinação de diferentes tipos de imagens (CBERS, Rapideye, SPOT, entre outras). Outras análises que exigem muitas observações por ano, como a detecção de incêndios, o monitoramento de corpos d'água 
ou a caracterização da resposta fenológica da vegetação, serão fortemente limitadas pela falta de observações válidas distribuídas homogeneamente ao longo do tempo.

Para ilustrar o efeito da frequência de observações sobre a caracterização da atividade fotossintética ao longo do ano, elaboraram-se perfis do Índice de Vegetação da Diferença Normalizada (NDVI) durante o período 2017-2019 para dos locais indicados em uma área da caatinga entre Irecê e Rio São Francisco no Estado da Bahia (Figura 11). Nos gráficos os pontos verdes, cinzas e azuis apresentam as observações de NDVI obtidas, respectivamente, pelo Landsat 7, Landsat 8 e Sentinel. As curvas foram geradas através do cálculo de uma mediana móvel. O primeiro local corresponde a uma área de vegetação densa e está localizado numa faixa de sobreposição das imagens Sentinel-2. Por esta razão existe um grande número de observações válidas do Sentinel-2 (250). O número de observações válidas para os dados do Landsat também é relativamente alto (23 e 40, respectivamente, para o Landsat 7 e 8). Na figura 11A, observa-se o comportamento espectral da vegetação com aumento do NDVI relacionado com o crescimento na atividade fotossintética durante o período de chuvas de dezembro a março. Também é notável que os índices de diferentes sensores apresentam um deslocamento e não são diretamente comparáveis. Também é possível verificar que observações do Sentinel apresentam valores muito inferiores a outras, mesmo estando próximas temporalmente. Estas observações correspondem provavelmente a nuvens que não foram detectadas pela máscara de nuvem QA60, como foi comentado anteriormente e reportado por Coluzzi et al. (2018).

A Figura 11B representa os valores de NDVI em uma área de vegetação mais esparsa e é baseada em um número menor de observações (11, 26 e 92 para o Landsat 7, Landsat 8 e Sentinel, respectivamente). Pode-se observar que os perfis baseados em poucas observações, em particular o perfil obtido com o Landsat 7, não permitem caracterizar as mudanças fenológicas de maneira confiável. Os dados do Sentinel-2, que apresentam uma melhor resolução temporal, permitem uma melhor caracterização das mudanças temporais na resposta da cobertura do solo. Nesse sentido, dados baseados na fusão de imagens de diferentes sensores são uma alternativa promissora. Por exemplo, a harmonização do Landsat e do Sentinel-2 (https://hls.gsfc.nasa.gov/) permite combinar os dados dos dois 
sensores e produzir um produto híbrido com uma resolução de cinco dias (CLAVERIE et al., $2018)$.

Figura 11 - Perfis temporais de NDVI de caatinga. A: vegetação densa, localizada nas coordenadas $-41,616$; -10,313; B: vegetação esparsa, localizada nas coordenadas -40.968 ; $-10,427$.
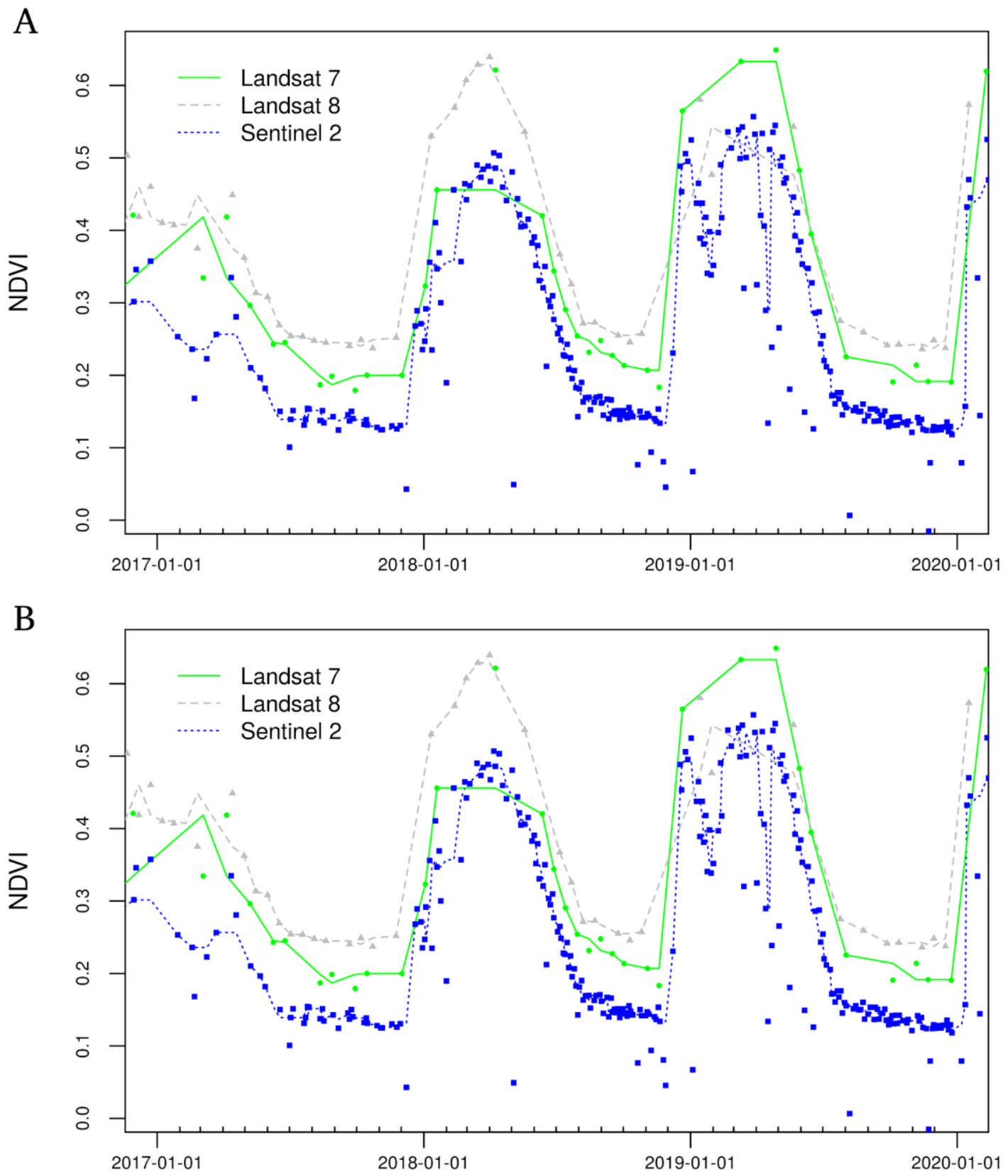

Fonte: Autores/as (2020) 


\section{CONSIDERAÇÕES FINAIS}

A política gratuita de distribuição de dados Landsat e Sentinel abriu uma nova era para a utilização desses dados. No entanto, devido à presença de nuvens, certos biomas, principalmente a Amazônia e, em menor grau, a Caatinga e a Mata Atlântica, apresentam poucos dados válidos e mal distribuídos no tempo. Os dados do Sentinel-2, que apresentam melhor resolução temporal e uma aquisição mais sistemática, têm um número muito maior de observações válidas por mês e são promissores para monitoramentos futuros. No entanto, a constelação de satélites Sentinel-2 começou a estar totalmente operacional a partir de 2018, portanto, para datas anteriores os dados do Landsat continuam sendo a base de muitos estudos e podem ser complementados por outros sensores, como CBERS, RapidEye, SPOT ou MODIS. As áreas de sobreposição entre duas faixas de imageamento contêm aproximadamente duas vezes mais observações e oferecem a oportunidade de realizar estudos baseados em séries de tempo ao longo de transectos norte-sul.

Por fim, cabe destacar que os autores disponibilizaram os mapas por cenas em formato shapefile em https://bit.ly/3eSBrkk (Landsat) e https://bit.ly/3cLwjfL (Sentinel-2). As imagens do número de observações válidas estão disponiveis em https://bit.ly/2VXpTn7 (Landsat) e https://bit.ly/2W1wa1d (Sentinel-2). Os códigos do Google Earth Engine estão também disponíveis em el link: https://github.com/JonathanVSV/Landsat-Sentinel-Obs.

\section{AGRADECIMENTOS}

O primeiro autor agradece ao Programa de Apoyos para la Superación del Personal Académico (Dirección General Asuntos del Personal, Universidad Nacional Autónoma de México) pelo apoio financeiro à realização de uma estadia sabática na Universidade Federal do Ceará.

\section{REFERÊNCIAS}

AB'SÁBER, A. N. Litoral do Brasil. São Paulo: Metalivros, 2005.

ASNER, G. P. Cloud cover in Landsat observations of the Brazilian Amazon. International Journal of

Remote Sensing, v. 22, n. 18, p. 3855-3862, 2001. DOI 10.1080/01431160010006926. 
AMANAJÁS, J. C.; BRAGA, C. C. Padrões espaço-temporal Pluviométricos na Amazônia Oriental utilizando Análise Multivariada. Revista Brasileira de Meteorologia, v.27, n.4, 323 - 338, 2012.

BARRY, R.G.; CHORLEY, R.J. Atmosfera, tempo e clima. Porto Alegre: Bookman, 2013.

BERGER, M.; MORENO, J.; JOHANNESSEN, J. A.; LEVELT, P. F.; HANSSEN, R. F. ESA's sentinel missions in support of Earth system science. Remote Sensing of Environment, v. 120, p. 84-90, 2012. DOI 10.1016/j.rse.2011.07.023.

BEZERRA, U. A.; OLIVEIRA, L. M. M.; CANDEIAS, A. L. B.; SILVA, B. B.; LEITE, A. C. L. D. S.; SILVA, L. T. M. D. S. Comparativo do Índice de Vegetação de Diferença Normalizada (NDVI) entre os Sensores OLISatélite Landsat-8 e MSI-Satélite Sentinel-2 em Região Semiárida. Anuário do Instituto de Geociências, v. 41, n. 3, p. 167-177, 2019.

CHEN, J.; ZHU, X.; VOGELMANN, J.; GAO, F.; JIN, S. A simple and effective method for filling gaps in Landsat ETM+ SLC-off images. Remote Sensing of Environment, v. 115, n. 4, p. 1053-1064, 2011. DOI 10.1016/j.rse.2010.12.010.

CLAVERIE, M.; JU, J.; MASEK, J. G.; DUNGAN, J. L.; VERMOTE, E. F.; ROGER, J.-C.; SKAKUN, S. V.; JUSTICE, C. The Harmonized Landsat and Sentinel-2 surface reflectance data set. Remote Sensing of Environment, v. 219, p. 145-161, 2018. DOI 10.1016/j.rse.2018.09.002.

CPTEC-INPE. Centro de Previsão do Tempo e Estudos Climáticos - Instituto Nacional de PEsquisas Espaciais. El Niño e La Niña. Disponível em <http://enos.cptec.inpe.br/>. Acesso em 24 set 2020.

COLUZZI, R.; IMBRENDA, V.; LANFREDI, M.; SIMONIELLO. T. A First Assessment of the Sentinel-2 Level 1-C Cloud Mask Product to Support Informed Surface Analyses. Remote Sensing of Environment, v. 217, p. 426-443, 2018. DOI 10.1016/j.rse.2018.08.009.

COPERTINO, M.; PIEDADE, M. T. F.; VIEIRA, I. C. G.; BUSTAMANTE, M. Desmatamento, fogo e clima estão intimamente conectados na Amazônia. Ciência e Cultura, 2019, São Paulo, v. 71, n. 4, p. 0405. DOI 10.21800/2317-66602019000400002.

DRUSCH, M., U. DEL BELLO, S. CARLIER, O. COLIN, V. FERNANDEZ, F. GASCON, [et al.]. Sentinel-2: ESA's Optical High-Resolution Mission for GMES Operational Services. Remote Sensing of Environment, v. 120, p. 25-36, 2012. DOI 10.1016/j.rse.2011.11.026.

EGOROV, A.V.; ROY, D.P.; ZHANG, H.K.; LI, Z.; YAN, L.; HUANG, H. Landsat 4, 5 and 7 (1982 to 2017) Analysis Ready Data (ARD) Observation Coverage over the Conterminous United States and Implications for Terrestrial Monitoring. Remote Sensing 2019, 11, 447. DOI 10.3390/rs11040447.

ESA (European Space Agency). Sentinel-2 User Handbook, 2015, 64 p. Disponível em: https://earth.esa.int/documents/247904/685211/Sentinel-2_User_Handbook. Acesso em: 11 maio 2020.

ESA (European Space Agency). Technical Guide Overview. Disponível em: https://sentinels.copernicus.eu/web/sentinel/sentinel-technical-guides. Acesso em: 20 abr. 2020.

ESA (European Space Agency). Sentinel-2 MSI Technical Guide, 2020b. Disponível em: https://sentinel.esa.int/web/sentinel/technical-guides/sentinel-2-msi. Acesso em: 12 mai 2020.

FRANCA, R. R. da; MENDONÇA, F. de A. A pluviosidade na Amazônia meridional: variabilidade e teleconexões extra-regionais. Confins, n. 29, p. 1-13, 11 dez. 2016. DOI 10.4000/confins.11580. 
FREIRE, J. L. M.; LIMA, J. R. A.; CAVALCANTI, E. P. Análise de Aspectos Meteorológicos sobre o Nordeste do Brasil em Anos de El Niño e La Niña. Revista Brasileira de Geografia Física, v. 4, n. 3, p. 429-444, set. 2011. doi: https://doi.org/10.26848/rbgf.v4.3.p429-444.

GEE - Google Earth Engine. What is Earth Engine? Disponível em: <https://earthengine.google.com/faq/>. Acesso em 13 nov 2020.

GOMES, D.D.M., MENDES, L.M.S., MEDEIROS, C.N. de, VERISSIMO, C.U.V.; Análise multitemporal do processo de degradação da vegetação da bacia hidrográfica do Rio Jaibaras no Estado do Ceará, Geografia Ensino \& Pesquisa, v. 15, n.2, p. 41-62, 2011.

GORELICK, N.; HANCHER, M.; DIXON, M.; ILYUSHCHENKO, S.; THAU, D.; MOORE, R. Google Earth Engine: Planetary-scale geospatial analysis for everyone, Remote Sensing of Environment, v. 202, p. 18-27, 2017. DOI 10.1016/j.rse.2017.06.031.

GRECCHI, R. C.; BERTANI, G.; TRABAQUINI, K.; SHIMABUKURO, Y. E.; FORMAGGIO, A. R. Análise espaço-temporal da conversão do cerrado em áreas agrícolas na região de Sapezal, Mato Grosso, entre os anos de 1981 e 2011. Revista Brasileira de Cartografia, v. 68, n. 1, 21 fev. 2016.

HANSEN, M.C.; LOVELAND, T.R. A review of large area monitoring of land cover change using Landsat data. Remote Sensing of Environment, v. 122, p. 66-74, 2012. DOI 10.1016/j.rse.2011.08.024.

HANSEN, M. C.; POTAPOV, P. V.; MOORE, R.; HANCHER, M.; TURUBANOVA, S. A.; TYUKAVINA, A.; [et al.]. High-Resolution Global Maps of 21st-Century Forest Cover Change. Science, v. 342, n. 6160, p. 850-853, 2013. DOI 10.1126/science.1244693.

INSTITUTO BRASILEIRO DE GEOGRAFIA E ESTATÍSTICA (IBGE). Manual técnico da vegetação brasileira : sistema fitogeográfico : inventário das formações florestais e campestres : técnicas e manejo de coleções botânicas : procedimentos para mapeamentos. Rio de Janeiro, 2012. Disponível em: <https://biblioteca.ibge.gov.br/visualizacao/livros/liv63011.pdf>. Acesso em: 6 maio 2020.

INSTITUTO BRASILEIRO DE GEOGRAFIA E ESTATÍSTICA (IBGE). Monitoramento de uso e cobertura da terra do Brasil. Rio de Janeiro, 2018. Disponível em: <https://www.ibge.gov.br/apps/monitoramento_cobertura_uso_terra/v1/>. Acesso em: 21 mar 2020.

INSTITUTO NACIONAL DE PESQUISAS ESPACIAIS (INPE). A estimativa da taxa de desmatamento por corte raso para a Amazônia Legal em 2019 é de 9.762 km². São José dos Campos, 2019. Disponível em: < http://www.inpe.br/noticias/noticia.php?Cod_Noticia=5294>. Acesso em: 20 mar 2020.

JENSEN, J. R. Sensoriamento remoto do ambiente: uma perspectiva em recursos terrestres. Tradução: José Carlos Neves Epiphanio (coord.) et al. São José dos Campos: Parêntese, 2009.

JU, J.; ROY, D.P. The availability of cloud-free Landsat ETM+ data over the conterminous United States and globally. Remote Sensing of Environment, 112, p. 1196-1211, 2008. DOI 10.1016/j.rse.2007.08.011

KOVALSKYY, V.; ROY, D.P. The Global Availability of Landsat 5 TM and Landsat 7 ETM+ Land Surface Observations and Implications for Global 30m Landsat Data Product Generation. GSCE Faculty Publications 49, 2013. Disponível em: https://openprairie.sdstate.edu/gsce_pubs/49. 
LI, J.; ROY, D. P. A Global Analysis of Sentinel-2a, Sentinel-2b and Landsat-8 Data Revisit Intervals and Implications for Terrestrial Monitoring. Remote Sensing, v. 9, n. 9, p. 902, 2017. DOI $10.3390 /$ rs9090902.

LIESENBERG, V.; LIMA, A. Estudo comparativo entre as estimativas de áreas florestadas a partir de dados TM/Landsat e MODIS/EOS-AM1. In: Congresso Brasileiro de Computação. 2004. p. 791-799.

LIZUNDIA-LOIOLA, J.; PETTINARI, M.L.; CHUVIECO, E. Temporal Anomalies in Burned Area Trends: Satellite Estimations of the Amazonian 2019 Fire Crisis. Remote Sensing. v. 12, 151, 2020. DOI $10.3390 /$ rs 12010151.

MAACK, R. Geografia física do Estado do Paraná. Ed. Banco de Desenvolvimento do PR. $1^{\text {a }}$ Edição. Curitiba-PR, 1968.

MAIA, M. A. M; MARMOS, J. L. Geodiversidade do Estado do Amazonas. Manaus: CPRM, 2010.

MANTOVANI, J. E.; PEREIRA, A. Estimativa da integridade da cobertura vegetal de Cerrado através de dados TM/Landsat. Simpósio Brasileiro de Sensoriamento Remoto, v. 9, p. 11-18, 1998.

MAS, J-F; HORTA, M.B., VASCONCELOS R.E.N.; CAMBUI E.C.B., Análise espacial com R, Feira de Santana: UEFS Editora, 102 p, 2019. ISBN: 978-85-5592-091-2. Disponível em: https://bit.ly/2KpSI7C

MAS, J-F.; LEMOINE-RODRIGUEZ, R.; \& TAUD, H. Toward a near-real time forest monitoring system (Technical note). Investigaciones Geográficas, v. 91, p. 168-175, 2016. DOI:10.14350/rig.56889

MELO, A. B. C.; CAVALCANTI, I. F de A.; SOUZA, P. P. Zona de Convergência Intertropical do Atlântico. In: CAVALCANTI, I. F. A.; FERREIRA, N. J.; SILVA, M. G. A. J.; DIAS, M. A. F. S. (Orgs.). Tempo e clima no Brasil. São Paulo: Oficina de Textos, 2009.

MONTEIRO, M. A. Dinâmica atmosférica e a caracterização dos tipos de tempo na Bacia Hidrográfica do Rio Araranguá. Tese: Doutorado em Geografia (UFSC). Florianópolis, 2007.

MOREIRA, M. Identificação de reflorestamentos por meio da análise quantitativa de imagens orbitais Landsat. 65 p. 1984. Dissertação (Mestrado), Universidade Federal de Viçosa, Viçosa.

NOVO, E. M. L. M. Sensoriamento remoto: princípios e aplicações. Edgard Blücher, 2008.

PONZONI, F. J.; HERNANDEZ FILHO, P.; PEREIRA, M.; LORENZI, C. A fisionomia da cobertura vegetal do Parque Nacional do Pantanal Matogrossense (PNPM) identificada através do sensor TM/LANDSAT: uma análise temporal. Simpósio Brasileiro de Sensoriamento Remoto, v. 5, p. 670$674,1988$.

R CORE TEAM. R: A Language and Environment for Statistical Computing, R Foundation for Statistical Computing, Vienna, Austria, 2020. https://www.R-project.org/

ROSA, M. B.; SILVA, L. T. Alguns Aspectos Climatológicos da ZCIT sobre o Atlântico. Climanálise Edição comemorativa de 30 anos, 2016.

SAMPAIO, R.C.; WACHHOLZ, F. Dinâmica da Agropecuária e o Mapeamento do Uso da Terra no Município de Manacapuru. Acta Geográfica, Boa Vista, v.12, n.30, p. 215-226, 2018. 
SANO, E.E.; FERREIRA, L.G.; ASNER, G.P.; STEINKE, E.T. Spatial and temporal probabilities of obtaining cloud-free Landsat images over the Brazilian tropical savanna. International Journal of Remote Sensing, v. 28, p. 2739-2752, 2007. DOI 10.1080/01431160600981517.

SANO, E. E.; ROSA, R.; BRITO, J. L. S.; FERREIRA, L. G.; BEZERRA, H. D. S. Mapeamento da cobertura vegetal natural e antrópica do bioma Cerrado por meio de imagens Landsat ETM+. Anais do Simpósio Brasileiro de Sensoriamento Remoto. INPE, Natal, p. 1199-1206, 2009.

SANTOS, J. R. Monitoring of Amazonian forest ecosystem: Present conjuncture on the use of remote sensing technology. Academia Brasileira de Ciências, v. 66, p. 109-109, 1994.

SILVA, J. P. R; REBOITA, M. S; ESCOBAR, G. C. J. Caracterização da Zona de Convergência do Atlântico Sul em Campos Atmosféricos Recentes. Revista Brasileira de Climatologia, v. 25, p. 355-377, 2019. Universidade Federal do Paraná. DOI 10.5380/abclima.v25i0.64101.

SOUZA, C.; Z. SHIMBO, J.; ROSA, M.; PARENTE, L.; A. ALENCAR, A.; RUDORFF, B.; HASENACK, H.; MATSUMOTO, M.; G. FERREIRA, L.; SOUZA-FILHO, P.; DE OLIVEIRA, S.; ROCHA, W.; FONSECA, A.; MARQUES, C.; DINIZ, C.; COSTA, D.; MONTEIRO, D.; ROSA, E.; VÉLEZ-MARTIN, E.; WEBER, E.; LENTI, F.; PATERNOST, F.; PAREYN, F.; SIQUEIRA, J.; VIERA, J.; NETO, L.; SARAIVA, M.; SALES, M.; SALGADO, M.; VASCONCELOS, R.; GALANO, S.; MESQUITA, V.; AZEVEDO, T. Reconstructing Three Decades of Land Use and Land Cover Changes in Brazilian Biomes with Landsat Archive and Earth Engine. Remote Sensing, 12(17), 2735, 2020. DOI 10.3390/rs12172735.

TAVARES, J. P. N. Características da Climatologia de Macapá - AP. Caminhos de Geografia, Uberlândia, v. 15, n. 50, p. 138-151, Jun/2014.

UNITED STATES GEOLOGICAL SURVEY (USGS). Landsat Science Products. Disponível em: $<$ https://www.usgs.gov/land-resources/nli/landsat/landsat-surface-reflectance?qt-

science_support_page_related_con=0\#qt-science_support_page_related_con>. Acesso em: 25 mar 2020.

VILANI, M.T.; SANCHES, L.; PINHEIRO, M.R; JUNIOR, O.B.P.; Estimativa da radiação de onda longa incidente em uma floresta semidecídua tropical da Bacia Amazônica. Ciência e Natura, UFSM, v. 32, n. 1, p. 65 - 81, 2010. DOI 10.5902/2179460X9498.

ZHANG, X.; FRIEDL, M.A.; SCHAAF, C.B. Sensitivity of vegetation phenology detection to the temporal resolution of satellite data, International Journal of Remote Sensing, v. 30, n. 8, p. 2061-2074, 2009. DOI 10.1080/01431160802549237.

ZHOU, Y.; DONG, J.; LIU, J.; METTERNICHT, G.; SHEN, W.; YOU, N.; ZHAO, G.; XIAO, X. Are There Sufficient Landsat Observations for Retrospective and Continuous Monitoring of Land Cover Changes in China? Remote Sensing, 11, 1808, 2019. DOI 10.3390/rs11151808 